J Venom Anim Toxins incl Trop Dis.

V.15, n.1, p.180, 2009.

Thesis.

ISSN 1678-9199.

\title{
MODULATORY EFFECTS OF TUBERCULOSIS VACCINES ON EXPERIMENTAL AUTOIMMUNE ENCEPHALOMYELITIS
}

Thesis: S. F. G. Zorzella-Pezavento submitted this dissertation for her Masters in Tropical Diseases at Botucatu Medical School, São Paulo State University, UNESP, Botucatu, São Paulo State, Brazil, 2008.

\section{Advisor: Professor Alexandrina Sartori}

ABSTRACT: Although BCG is the only accepted vaccine against tuberculosis (TB), its protective ability is very limited. Therefore, many new vaccines are being evaluated. Our group has been working on DNAhsp65 - a genetic construction containing the hsp65 gene from Mycobacterium leprae. In previous experimental works, we demonstrated that both DNAhsp65 alone or associated with BCG, in a prime-boost regimen, were effective to control TB. A possible deleterious effect related to autoimmunity needed to be tested because hsp65 is highly homologous to the correspondent mammalian protein. In this investigation we tested the effect of a previous immunization with DNAhsp65 alone or associated with BCG in a rat model of multiple sclerosis. Female Lewis rats were immunized with three doses of DNAhsp65 or primed with BCG followed by two DNAhsp65 boosters. The animals were, then, immunized with myelin associated with complete Freund's adjuvant to develop experimental autoimmune encephalomyelitis (EAE). The following parameters were evaluated: weight loss, clinical score, central nervous system (CNS) inflammation and antimyelin immune response. No deleterious effect was associated with these immunizations schedules. Immunized animals equally lost weight, the clinical scores were similar and CNS inflammation did not increase. Interestingly, both procedures determined decreased inflammation in the brain and lumbar spinal cord. This was concurrent with a modulatory effect over cytokine production by peripheral lymphoid organs. Cell cultures from spleen and lymph nodes in vitro stimulated with myelin produced less IFN-gamma and IL-10, respectively. This phenomenon was more clear in rats immunized with the genetic vaccine alone than with the prime-boost strategy. Together the results suggest that these strategies for TB prophylaxis would not accelerate or aggravate multiple sclerosis, being therefore, safe in this aspect. In addition, they indicate that these vaccination regimens have a potential antiinflammatory activity that could be better explored in the future.

KEY WORDS: experimental autoimmune encephalomyelitis, DNA vaccine, hsp65, BCG, tuberculosis.

\section{CORRESPONDENCE TO:}

SOFIA FERNANDA GONÇALVES ZORZELLA PEZAVENTO, Departamento de Microbiologia e Imunologia, Instituto de Biociências, UNESP, Botucatu, SP, Brasil. Phone: +55 143811 6240. Fax: +55 143815 3744. Email: szorzella@yahoo.com.br. 